\title{
Pattern recognition approach and clinico-radiological evaluation of compressive myelopathies at a tertiary care hospital
}

\author{
Kiran J.S. ${ }^{1}$, Rao M. ${ }^{2}$, Pasha 5. ${ }^{3 *}$ \\ DOI: https://doi.org/10.17511/ijmrr.2020.i01.04 \\ ${ }^{1}$ Kiran J.S., Postgraduate, Department of Medicine, NRI Medical College and General Hospital, Guntur, Andhra Pradesh, India. \\ 2 M Nageswara Rao, Professor, Department of Neurology, NRI Medical College and General Hospital, Guntur, Andhra Pradesh, India. \\ 3* SK Afsar Pasha, Professor, Department of Neurology, NRI Medical College and General Hospital, Guntur, Andhra Pradesh, India.
}

Background: Neuroimaging is indicated in most instances of new-onset myelopathy for clinicoradiological correlation in terms of diagnosis, recovery, and prediction of recurrence. Aim: This study was conducted to study the clinical profile of cases of Compressive Myelopathy and the pattern of spinal cord involvement, also to compare the sites of localisation of clinical diagnosis with MRI diagnosis. Methodology: The present study was a prospective study involving 30 patients. Patients with clinical suspicion of spinal cord disease of age group 20-80 years were included as study participants. The primary pulse sequences included T1 and T2 weighted images on MRI, the location of the lesion, its margins, signal intensity on both $\mathrm{T} 1$ and $\mathrm{T} 2$ weighted images was noted. Results: The majority of $53.33 \%$ of participants were aged between 51 to 60 years. Difficulty in walking was observed in $97 \%$ of participants. Men were more often affected than women. Cervical spondylosis was the commonest cause of compressive myelopathy in 57\%. A most common pattern of spinal cord involvement was combined Anterior + Posterior cord involvement. The cervical site of localisation (54\%) was the commonest followed by the thoracic and lumbar spinal cord. Conclusion: Myelopathies have male preponderance. The commonest cause of compressive myelopathy was Cervical spondylosis. Anterior plus posterior cord syndrome was the commonest pattern seen, followed by posterior cord syndrome, anterior cord syndrome being the least observed. MRI correlates well with a clinical diagnosis and is useful in suggesting the location of the lesion.

Keywords: Cervical spondylosis, Compressive myelopathy, Spinal cord syndromes

Corresponding Author

SK Afsar Pasha, Professor, Department of Neurology, NRI Medical College and General Hospital, Guntur, Andhra Pradesh, India.

Email: afsarpasha81@gmail.com

\section{How to Cite this Article}

Kiran JS, Rao MN, Pasha SKA. Pattern recognition approach and clinico-radiological evaluation of compressive myelopathies at a tertiary care hospital. Int J Med Res Rev. 2020;8(1):24-30.

Available From

https://ijmrr.medresearch.in/index.php/ijmrr/article/ view/1135
To Browse

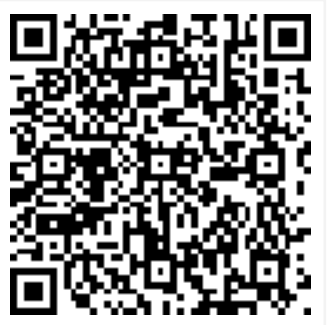

Manuscript Received 2019-11-26

Conflict of Interest No
Review Round 1 2019-12-04

Funding $\mathrm{Nil}$

Review Round 2
2019-12-10
$\begin{gathered}\text { Ethical Approval } \\ \text { Yes }\end{gathered}$

Review Round 2 Yes
Review Round 3

Plagiarism X-checker $5 \%$
Accepted 2019-12-14

Note

(c) 2020 by Kiran J.S., M Nageswara Rao, SK Afsar Pasha and Published by Siddharth Health Research and Social Welfare Society. This is an Open Access article licensed under a Creative Commons Attribution 4.0 International License https://creativecommons.org/licenses/by/4.0/ unported [CC BY 4.0]. 


\section{Introduction}

Spinal cord dysfunction is a common neurological problem, which may have an obvious traumatic or compressive cause. Beyond this, the lack of pathological specificity of the clinical and imaging features means that patients are often treated empirically, based on the prevalence and the treatability of the differential diagnoses; multiple sclerosis (MS) and isolated inflammatory myelitis are the most likely diagnoses in the western world [1].

Myelopathy describes any neurologic deficit related to the spinal cord. Myelopathy is usually due to compression of the spinal cord by osteophyte or extruded disc material in the cervical spine. Osteophytic spurring and disc herniation may also produce myelopathy localised to the thoracic spine, though less commonly [2]. Myelopathy, the rapid or insidious onset of motor and sensory abnormalities referable to the spinal cord, occurs as a result of a variety of causes that may be classified on the basis of their location of origin (intramedullary, intraduralextramedullary, and extradural) [3].

Degenerative cervical myelopathy (DCM) is a progressive spine disease and the most common cause of spinal cord dysfunction in adults worldwide [4]. With the aging of the global population, clinicians will be required to manage an increasing number of patients with degenerative changes to their spine and varying stages of myelopathy [5]. Cervical spondylotic myelopathy is the result of the narrowing of the cervical spinal canal by degenerative and congenital changes [6]. Cervical spondylotic myelopathy (CSM) is the leading cause of myelopathy in subjects above 55 years old and the major cause of spasticity acquired in the aged population [7].

Although a survey of the entire spinal cord can be performed with imaging, it is more appropriate to define from the clinical findings what levels of the spine and spinal cord should be imaged. This approach helps limit the likelihood of false-positive imaging findings that may encourage needless attempts to fix what is not broken [8]. For most patients presenting with a spinal cord syndrome, MR scanning has become the key investigation in establishing the diagnosis. However, myelopathy with normal spinal imaging remains a common clinical conundrum [9]. Hence a
Current study was conducted to study the clinical profile of cases of compressive Myelopathy and the pattern of spinal cord involvement, also to compare the clinical diagnosis with MRI diagnosis.

\section{Materials and Methods}

Study setting: The study was conducted on patients admitted in the departments of neurology and neurosurgery with clinical suspicion of spinal cord disease.

Study design: The current study was a prospective study.

Study period: The study was conducted between January 2017 to December 2017.

Sample size: The present prospective study included 30 patients admitted in the departments of neurology and neurosurgery with clinical suspicion of spinal cord disease.

Inclusion criteria: Inclusion criteria include patients with clinical suspicion of spinal cord disease of age group 20-80 years were included as study participants in the present study

Exclusion criteria: The current study excluded patients with seizures, abnormal higher mental functions, and children.

Data collection procedure: Collection of complete data regarding the history of the patient, age, sex, MRI and relevant investigations. A complete physical examination was also conducted and systemic examination. MRI was performed on a 1.5tesla machine. The primary pulse sequences included $\mathrm{T} 1$ and $\mathrm{T} 2$ weighted images on MRI, the location of the lesion, its margins, signal intensity on both T1 and T2 was noted. MRI was done in all cases and the findings were as follows: - Vertebral changes, disc space changes, bony canal changes, ligamentous changes, thecal indentation, pressure changes over the spinal cord.

Ethical consideration and permission: The study was approved by the institutional human ethical committee. All the included participants have provided informed written consent for participation in the study. Care was taken to maintain the confidentiality of the personal information of participants.

Data analysis: Statistical analysis was performed using MS Excel software and data was 
Expressed as frequencies and percentages for categorical variables. IBM SPSS version 22 was used for statistical analysis [10].

\section{Results}

In the present series, the patient's age ranged from 20 years to 80 years. The maximum incidence is in the third to sixth decade constituting $72 \%$ of cases. The majority of $53.33 \%$ of participants were aged between 51 to 60 years, followed by 61 to 70 years was $13.33 \%, 21$ to 30 years and 41 to 50 was $10 \%$ for each. In the present series, 28 (93\%) participants were male and 2 (7\%) participants were female (Table 1 ).

Clinical Features: Clinical features of spinal cord compression vary depending upon the sources of compression and the tracts involved in the spinal cord. The incidence of various symptoms and signs are shown in the following table. The highest number is with weakness of all 4 limbs. The majority of $97 \%$ of participants had difficulty in walking, followed by tingling and numbness, pain weakness of upper and lower limbs, and loss of muscle mass was $87 \%, 83 \%, 70 \%$, and $47 \%$ respectively. ONSET: The onset in the present series varied from a few hours to 2 years. Onset varied with the site of involvement and the nature of etiology onset was rapid whenever there is associated factor-like trauma. The onset was acute in $30 \%$ of cases. Motor Power: Grading of motor power was done according to the medical research council. In the present series grade ' 0 ' power was present in four cases grade 1-2 in four cases, grade 3 power in five cases, grade 4 power in sixteen cases, grade 5 in one case. (Table 2)

Table-1: Distribution of cases according to age and sex.

\begin{tabular}{|c|c|c|}
\hline Parameter & Number of patients $(\mathrm{N}=\mathbf{3 0})$ & Percentage \\
\hline \multicolumn{3}{|l|}{ Age } \\
\hline $21-30$ & 3 & 10 \\
\hline $31-40$ & 2 & 6.66 \\
\hline 41-50 & 3 & 10 \\
\hline $51-60$ & 16 & 53.33 \\
\hline $61-70$ & 4 & 13.33 \\
\hline 71-80 & 2 & 6.66 \\
\hline \multicolumn{3}{|l|}{ Gender } \\
\hline Males & 28 & $93 \%$ \\
\hline Females & 2 & $7 \%$ \\
\hline
\end{tabular}

Table-2: Distribution of cases according to signs, symptoms, onset and motor power.

\begin{tabular}{|c|c|c|}
\hline Parameter & No. of patients & Percentage \\
\hline \multicolumn{3}{|l|}{ Signs/symptoms } \\
\hline Difficulty in walking & 29 & 97 \\
\hline Tingling and numbness & 26 & 87 \\
\hline Pains & 25 & 83 \\
\hline The weakness of upper and lower limbs & 21 & 70 \\
\hline Loss of muscle mass & 14 & 47 \\
\hline The weakness of lower limbs alone & 9 & 30 \\
\hline Bowel and bladder & 9 & 30 \\
\hline The weakness of one upper limb & 1 & 3 \\
\hline \multicolumn{3}{|l|}{ ONSET } \\
\hline Sub-acute and Chronic & 27 & 90 \\
\hline Acute onset & 3 & 10 \\
\hline \multicolumn{3}{|l|}{ Motor Power } \\
\hline Grade 0 & 4 & 13.33 \\
\hline Grade $1-2$ & 4 & 13.33 \\
\hline Grade 3 & 5 & 16.66 \\
\hline Grade 4 & 16 & 53.33 \\
\hline Grade 5 & 1 & 3.33 \\
\hline
\end{tabular}

Table-3: Distribution of cases according to etiology (MRI imaging diagnosis).

\begin{tabular}{|l|l|l|}
\hline \multicolumn{1}{|c|}{ Etiology } & No. of cases & Percentage \\
\hline Cervical spondylosis & 17 & 57 \\
\hline Caries Spine & 4 & 13 \\
\hline Vertebral Fracture & 3 & 10 \\
\hline Fluorosis & 2 & 7 \\
\hline Spinal tumor & 1 & 3 \\
\hline Others & 3 & 10 \\
\hline
\end{tabular}

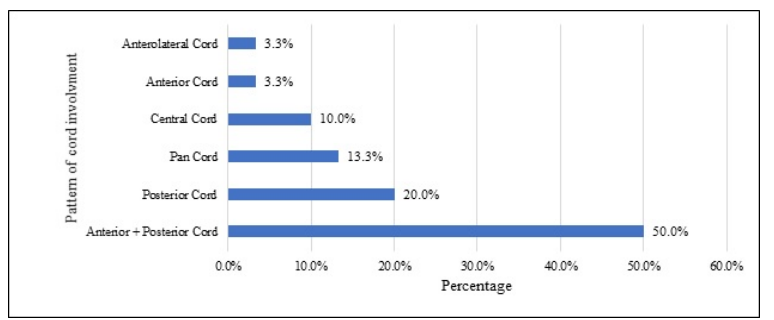

Fig-1: Bar chart showing the distribution of cases according to the pattern of cord involvement

Distribution of cases according to etiology: Among the study population, 17 (57\%) participants had cervical spondylosis, 4 (13\%) participants had caries spine, 3 (10\%) participants had a vertebral fracture and others for each, 2 (7\%) participants had fluorosis and only 1 (3\%) participant had spinal tumor (Table 3).

Clinico-radiological patterns of spinal cord syndromes: The majority of $50 \%$ of participants had Anterior + Posterior Cord involvement. The proportion of posterior cord, pan cord, and the 
Central cord was 20\%, $13.33 \%$, and $10 \%$ respectively (Figure 1 ).

Imaging findings of the study participants: In the case of cervical spondylosis, there was a decrease in the height of the vertebral body. There is bulging of the intervertebral disc causing indentation of theca of the cord. Dehydration of intervertebral discs is noted. The bulging of the disc material on the spinal cord has produced myelomalacia in some cases. The thickening of the posterior longitudinal ligament is seen in some cases.

In our series, six cases of dorsal vertebrae and four cases of lumbar vertebrae were involved. Involvement of bodies, disc space, posterior elements causing loss of height of vertebrae with severe cord compression with edema was noted. These were seen as hypointensity with T1W and hyperintensity with $\mathrm{T} 2 \mathrm{~W}$ images as observed in vertebrae due to destruction. Two cases of Endemic Fluorosis were noted in the present study forming $7 \%$. Radiologically both cases showed straightening of C-spine with degenerative endplate changes, thickening of posterior longitudinal ligament particularly between C2-C6 levels in one case, there was the narrowing of spinal cord dimensions compromising at $\mathrm{C} 3-\mathrm{C} 4$ level causing cord compressions with myelomalacia changes in the second case. One case of neurofibroma presenting as an extradural mass in $\mathrm{T} 2$ weighted images impinging spinal cord and extension into the neural foramina without any destruction of bone.

\section{Discussion}

Myelopathy is a broad term that refers to spinal cord involvement of multiple etiologies. Spinal cord diseases often have devastating consequences, ranging from quadriplegia and paraplegia to severe sensory deficits due to its confinement in a very small area.

Many of these diseases are potentially reversible if they are recognized on time, hence the importance of recognizing the significance of magnetic resonance imaging when approaching a multifactorial disease considered as one of the most critical neurological emergencies, where prognosis depends on an early and accurate diagnosis [11].

Narrowing (stenosis) of the spinal canal may result in myelopathy anywhere along the spinal axis, where the spinal cord is present. A common cause of acquired stenosis resulting in myelopathy is
Degenerative changes (spondylosis). These pathological changes are the same in the thoracic spine as those changes found in the lumbar and cervical regions and increase with age, yet the frequency of myelopathy as a result of these changes is less in the thoracic spine than in the cervical spine [12].

The clinical diagnosis of myelopathy requires a detailed history and physical examination to define the clinical syndrome. Neuroimaging is indicated in most instances of new-onset myelopathy [8]. MRI is the definitive modality in assessing spinal soft tissue injuries, especially in the evaluation of spinal cord, intervertebral discs, and ligaments. It also allows differentiating spinal cord haemorrhage and edema which may have a prognostic value. In the case of spinal trauma, MRI demonstrates the relationship of fractured/subluxated vertebral bodies to the cord and highlights significant stenosis.

In suspected cord compression due to neoplasm MRI serves as an excellent method for imaging tumors involving spinal column, canal, and cord. Of all the areas of spinal pathology, it may be in the field of spinal tumors that MRI has had the most impact. Today, MR is considered the procedure of choice for the work-up of all spinal tumors [13].

The present study included the majority of participants in between the age group of 51-60 years and showed a predominance of the male population. A study conducted in Bangladesh on patients with non-traumatic myelopathy also included the highest number of patients $(26.0 \%)$ in the age group 51-60 years [14].

The age group of patients of a retrospective study conducted in Tikur Anbessa Hospital did not match with our participants as the majority were between the age group of 16-30 years of age but their data also showed male predominance [15]. An observational study concluded that cervical myelopathy predominantly affects men in their 7th decade of life [16]. In another research, Myelopathy was three times more common in male than female [17].

Difficulty in walking was the major sign observed in the current study participants. The findings of the study conducted by Malone, A et al[18], suggested that people with cervical spondylotic myelopathy have significant gait abnormalities. The study conducted by Kumar, PS et al [19], showed that clinical evaluation showed limb weakness in all, sensory loss in 90\%, sphincter disturbances in 
$67.7 \%$, scissoring gait in $32.2 \%$, diaphragmatic weakness in $12.9 \%$ of patients. Myelopathy may result in little or no dysfunction-or severe dysfunction with gait disturbances [20]. Results of the study by Nishimura, $\mathrm{H}$ et al[21], suggested that when the percentage of the stance phase in the gait cycle increased to above $70 \%$, the CSM patients had an increased fall risk. A case report and review of the literature reported that the patient developed cervical radiculopathy, followed by gait disturbance and motor weakness [22].

Cervical motion segment disorders are considered to be multifactorial, and the developmental size of the canal and foramina, pathological encroachment, biomechanical effects, and circulatory deficiencies are always present to some degree. Static and dynamic factors should be considered for the development of myelopathy. To clarify the pathomechanism of the development of myelopathy in patients with cervical spondylotic spinal cord compression, the exact natural history of CSM should be understood [23].

Cervical spondylotic myelopathy (CSM) is the leading cause of myelopathy in subjects above 55 years old and the major cause of spasticity acquired in the aged population. More than $50 \%$ of middleaged people have radiographic evidence of cervical alteration, yet only $10 \%$ have symptoms of spinal cord compression or cervical radiculopathy $[6,7,24]$. In the present study cervical spondylosis was common according to etiology.

Similar results were found by the investigators of the study conducted in Bangladesh where investigators found among etiologies that cervical spondylotic myelopathy (31\%) was most commonly diagnosed [25]. The cervical myelopathy syndrome was first described in 1952, in some cases performed by Brain and colleagues [26]. In an extensive literature search, it was concluded that the prevalence of surgically treated cervical spondylotic myelopathy was estimated as 1.6 per 100,000 inhabitants [27].

Faysal MM et al [17]. Cervical spondylotic myelopathy and transverse myelopathy was the main etiology of compressive and non-compressive myelopathy respectively. The current study revealed that the cervical cord was more commonly involved. Similarly, Erdal, $\mathrm{Y}$ et al [28], found that common involvement of Cervical cord compared to other regions of the cord. It was found that only 2 participants presented with fluorosis. Gupta, RK et
Al [29], in their research found that Cord compression due to ossification of the posterior longitudinal ligament (PLL) and ligamentum flavum (LF) was demonstrated in one and ossification of only the LF in one. The marrow signal was observed in the PLL and LF in all the patients on all pulse sequences. Hence, they concluded that in patients with compressive myelopathy secondary to ossification of PLL and/or LF, fluorosis should be considered as a possible cause, especially in endemic regions.

Disc Prolapse was commonly seen in 4,5 , 6th cervical vertebrae in 6 of 17 in our series. In six cases there was the narrowing of neural foramina also. In eight cases degenerative endplate changes with osteophyte formation is present. All the above findings are better visualised in T2 Weighted images. Of the 17 cases of cervical spondylosis, MRI delineated the disc bulges, osteophytes, canal narrowing, and myelomalacia.

Only the MRI consistently showed that changes in the spinal cord result from compression. They were best seen on T2 weighted images. The distribution was characteristic consisting of diffuse signal changes at the site of maximal compression and variable extension to the central cord as already enlightened by Mehali, TF. [25].

Results of the previous study revealed that the MRI of the cervical spine demonstrated spinal canal stenosis due to disc bulging and flavum hypertrophy at the $\mathrm{C} 5 / \mathrm{C} 6$ and $\mathrm{C} 6 / \mathrm{C} 7$ levels as well as hyperintense area over the C5-C7 levels on T2weighted images [22]. In the present study, three cases of Syringomyelia were found. Spinal cord showed bulge at C5-T1 vertebral levels with central T1 hypointense and T2 hyperintense lesion which was suppressed on FLAIR images suggestive of Syringohydromyelia $[26,27]$.

\section{Limitations}

The key limitation of the current study is crosssectional and descriptive nature of the study. Hence no statistical association could be tested. The study is a hospital-based study, conducted with limited sample size, hence these results cannot be generalized for a larger group of population. In Future more research should be done in this locale including a larger study population to widen the spectrum of etiologies of compressive myelopathies so that tailor-made approach of the treatment is created that can be delivered without delay. 


\section{Conclusion}

The present study results have analyzed the profile of myelopathies and found more male preponderance. The commonest cause of compressive myelopathy was Cervical spondylosis. Anterior plus posterior cord syndrome was the commonest pattern seen which was followed by posterior cord syndrome and the least observed pattern was anterior cord syndrome. Hence, it can be concluded that MRI could suggest the location of the lesion and correlated well with clinical diagnosis. Magnetic resonance imaging was found to be highly useful in the evaluation of compressive lesions of the spinal cord.

\section{What the study adds to the existing knowledge}

Myelopathies are rare but severe disabling neurological illness. Cervical spondylosis is the most common cause. The etiology can be varied.

\section{Author's contribution}

Dr. Jakkula Sri Kiran had conceptualized the study, prepared the study protocol, conducted the data collection, analysis, and manuscript writing. He has verified all the drafts and approved the final draft. Dr. Shaik Afsar Pasha and Dr. M Nageswara Rao had provided key inputs on methodology during protocol preparation, supported data compilation, and analysis. He has also edited all the drafts and approved the final draft of the manuscript.

\section{Acknowledgments}

Authors acknowledge the technical support in data entry, analysis and manuscript editing by "Evidencian Research Associates."

\section{Reference}

01. Mariano R, Flanagan EP, Weinshenker BG, Palace J. A practical approach to the diagnosis of spinal cord lesions. Pract Neurol. 2018;18(3)187-200. doi: [Article] [Crossref]

02. Seidenwurm DJ. Expert Panel on Neurologic I, Myelopathy. AJNR Am J Neuroradiol. 2008;29(5)1032-1034.

[Crossref]
03. Rothman MI, Zoarski GH, Akhtar N. Extradural causes of myelopathy. Semin Ultrasound CT MR. $1994 ; 15(3) 226-249$.

doi: [Article] [Crossref]

04. Fehlings MG, Tetreault LA, Riew KD, Middleton JW, Aarabi B, Arnold PM, et al. A Clinical Practice Guideline for the Management of Patients With Degenerative Cervical MyelopathyRecommendations for Patients With Mild, Moderate, and Severe Disease and Nonmyelopathic Patients With Evidence of Cord Compression. Global Spine J. 2017;7(3)70S835 .

doi: [Article] [Crossref]

05. Fehlings MG, Tetreault $L$, Nater A, Choma T, Harrop J, Mroz T, et al. The Aging of the Global Population- The Changing Epidemiology of Disease and Spinal Disorders. Neurosurg. 2015;77(4)S1-S5.

doi: [Article] [Crossref]

06. McCormick WE, Steinmetz MP, Benzel EC. Cervical spondylotic myelopathy- make the difficult diagnosis, then refer for surgery. Cleve Clin J Med. 2003;70(10)899-904.

doi: [Article] [Crossref]

07. Klineberg E. Cervical spondylotic myelopathy- a review of the evidence. Orthop Clin North Am. 2010;41(2)193-202.

doi: [Article] [Crossref]

08. Marquis BO, Capone PM. Chapter 52 Myelopathy, Handbook of Clinical Neurology. 136- Elsevier. 2016;p- 1015-1026.

[Crossref]

09. Wong SH, Boggild M, Enevoldson TP, Fletcher NA. Myelopathy but normal MRI- where next?. Pract Neurol. 2008;8(2)90-102. doi: [Article] [Crossref]

10. IBM Corp. IBM SPSS Statistics for Windows, Version 22,0 Armonk. NY- IBM Corp. 2013. [Crossref]

11. Granados S, Ana M, Garcia P, Lina M, Ortega T, Cesar A, et al. Diagnostic approach to myelopathies. Revista Colombiana de Radiología. 2011;22(3)3231-3251. [Crossref]

12. Gay CW, Bishop MD, Beres JL. Clinical presentation of a patient with thoracic myelopathy at a chiropractic clinic. J Chiropr Med. 2012;11(2)115-120.

doi: [Article] [Crossref] 
13. Sarathchand V, Sambasivarao K, Anuradha B, Sudharani B. Role of MRI in the Evaluation of Compressive Myelopathy. OSR J Dent Med Sci. 2016;15(4)21-26.

doi: [Article] [Crossref]

14. Haleem MA, Islam MS, Quraishi F, Hossain S, Gosh L, Wadud MS, Mohammed Shoab A. Magnetic Resonance Imaging-Based Evaluation of the Etiology of Non-Traumatic Myelopathies in Bangladesh- A Hospital-based Observational Cross-sectional Study from Two Tertiary Care Centers of Dhaka. JNINB. 2020;4(2)87-91. doi: [Article] [Crossref]

15. Fidele NJ, Amanuel A. Spectrum of nontraumatic myelopathies in Ethiopian patients: hospitalbased retrospective study. Spinal Cord. 2016;54(8)604-608.

doi: [Article] [Crossref]

16. Northover JR, Wild JB, Braybrooke J, Blanco J. The epidemiology of cervical spondylotic myelopathy. Skeletal Radiol. 2012;41(12)15431546.

doi: [Article] [Crossref]

17. Faysal MM, Sutradhar SR, Saha SK, Nuary N, Hosen MA, Talukder RK, et al. Aetiology of Myelopathy in a Tertiary Hospital of Bangladesh. Mymensingh Med J. 2019;28(2)268-273.

[Crossref]

18. Malone A, Meldrum D, Bolger C. Gait impairment in cervical spondylotic myelopathycomparison with age- and gender-matched healthy controls. Eur Spine J. 2012;21(12)245666.

doi: [Article] [Crossref]

19. Kumar PS, Kalpana RY. Clinico-radiological correlation in a cohort of cervical myelopathy patients. J Clin Diagn Res. 2015;9(1)TC01TC07. doi: [Article] [Crossref]

20. Ann M, Henwood H. Cervical spondylosis with myelopathy- painful and sometimes paralyzing. Am Nurse Today. 2011;6;6.

[Crossref]

21. Nishimura $H$, Endo $K$, Suzuki $H$, Tanaka $H$, Shishido T, Yamamoto K. Gait Analysis in Cervical Spondylotic Myelopathy. Asian Spine J. 2015;9(3)321-6.

doi: [Article] [Crossref]
22. Okada S, Chang C, Chang G, Yue JJ. Venous hypertensive myelopathy associated with cervical spondylosis. Spine J. 2016;16(11)e751e754. doi: [Article] [Crossref]

23. Matsunaga S, Komiya S, Toyama Y. Risk factors for development of myelopathy in patients with cervical spondylotic cord compression. Eur Spine J. $2015 ; 24(2) 142-149$. doi: [Article] [Crossref]

24. Wang SQ, Li X, Cui JL, Li HX, Luk KD, Hu Y. Prediction of myelopathic level in cervical spondylotic myelopathy using diffusion tensor imaging. J Magn Reson Imaging. 2015;41(6)1682-1688. doi: [Article] [Crossref]

25. Haleem MA, Islam MS, Quraishi FA, Hossain S, Gosh L, Wadud MS, et al. Magnetic Resonance Imaging-Based Evaluation of the Etiology of Non-Traumatic Myelopathies in Bangladesh- A Hospital-based Observational Cross-sectional Study from Two Tertiary Care Centers of Dhaka. J Nat Instit Neurosci Bangladesh. 2018;4(2)8791.

doi: [Article] [Crossref]

26. Lavelle WF, Bell GR. Cervical myelopathyhistory and physical examination. Seminars in Spine Surgery, 19; Elsevier. 2007; p- 6-11. [Crossref]

27. Boogaarts HD, Bartels RH. Prevalence of cervical spondylotic myelopathy. Eur Spine J. 2015;24(2)139-141. doi: [Article] [Crossref]

28. Erdal Y, Emre U, Darliance ZS, Lean OÖ, Kılıçkesmez NÖ. Myelopathy- Retrospective Evaluation of Twenty-Eight Cases. Turk J Norol. 2017;23(4)186-192.

[Crossref]

29. Gupta RK, Agarwal P, Kumar S, Surana PK, Lal JH, Misra UK. Compressive myelopathy in fluorosis- MRI. Neuroradiol. 1996;38(4)338342. doi: [Article] [Crossref] 